\title{
Cautious delight at Baikonur as Soviet shuttle touches down
}

\section{Baikonur}

Buran, a Soviet reusable spaceship, made its maiden flight on the morning of 15 November, at the second attempt. The first, two weeks earlier, was automatically aborted because of a fault in the communications. But this time the entire launching equipment, the Energia booster and the reusable spaceship, performed smoothly.

Work on the Energia-Buran space system has been under way in the Soviet Union for roughly ten years. In its technical concepts, it differs greatly from the US shuttle. Having plumped for shuttle spacecraft, the United States almost completely abandoned one-shot rockets. It was supposed that, with a sufficiently large number of flights - up to a dozen a year - shuttles would be more effective. But experience has shown that it is difficult to maintain such a schedule and cost savings have not been achieved.

Alexander Dunayev, head of Glavkosmos, says that the efficiency of manned space-flight, and its rewards, are also current problems in the Soviet Union. But, he says, "by using existing technology, the expense can be repaid". One Soviet objective now, he says, is to develop the commercial aspect of space.

Dunayev also says that it is "disadvantageous - both economically and technically - to use only one vehicle, which is why we have built several, bearing in mind that they will be in service for many years". There is no intention to use them intensively, making 20-30 flights a year, for example.

According to Dunayev, Soviet engineers have never raised the question of abandoning one-shot booster rockets, which will continue to perform the main work of space transport. But "reusable vehicles will make it possible to carry out some specific tasks such as the delivery of specialists to orbit, the repair of equipment in space or its removal back to the Earth".

As a rule, Dunayev says, reusable vehicles will be used when it is necessary to carry extra cargo to a ship already launched. As things are, he says, the cost of launching a payload by the reusable system is tens or hundreds of times greater than by a one-shot rocket.

The take-off mass of Energia-Buran is 2,400 tonnes, of which 90 per cent is fuel. The ship itself weighs 105 tonnes, with a 30 -tonne payload. (The return payload is 20 tonnes.) While the characteristics of the Buran and the US shuttle are in many ways comparable, the Soviet system is more powerful - it has to be, however, because the US launching sites are nearer

\section{the Equator}

Heating of Buran on return to the atmosphere can raise the external temperature to $1,600{ }^{\circ} \mathrm{C}$, but the hull is protected by 30,000 quartz-carbon composite tiles with a total weight of 9 tonnes. Apart from the propulsion engines, there are two sets of smaller control engines near the crew cabin and in the tail section, all fed from a tank containing 14 tonnes of fuel. The maximum flight span in 30 days.

The Soviet Union began the development of Buran, in parallel with the Energia rocket, in 1977-78. The designers

\section{Rival shuttle judged}

\section{Washington}

WESTERN experts are now asking how the Soviet shuttle programme was able to advance so far so quickly. Until the shuttle was unveiled last month, it was not clear that the Soviet Union had mastered the technology needed to fly a shuttle or even accepted the arguments for manned cargocarrying space flights.

Soviet space experts have frequently criticized the US space shuttle programme as unnecessary and have stressed the development of large unmanned rockets. But the apparent change in direction may be partly related to internal Soviet politics, according to John Pike, director for space policy at the Federation of American Scientists. The shuttle project, he says, appears to have come out of the Aviation Ministry rather than the Machine Building Ministry which manufactures rockets and has dominated the space programme in the past.

A desire to keep up with the United States in shuttle design may be a factor, but it seems that the Soviet planners have come round to the view that a shuttle is the most convenient means of servicing and supplying orbiting manned space stations.

With Buran and its sister craft, the Soviet Union will be able to bring back scientific instruments, astronomical telescopes and machinery from the space station for repair as well as materials manufactured under gravity-free conditions. It will also be able to match the US shuttle's proven ability to pick up and return malfunctioning satellites. Two teams of designers arriving at similar conclusions

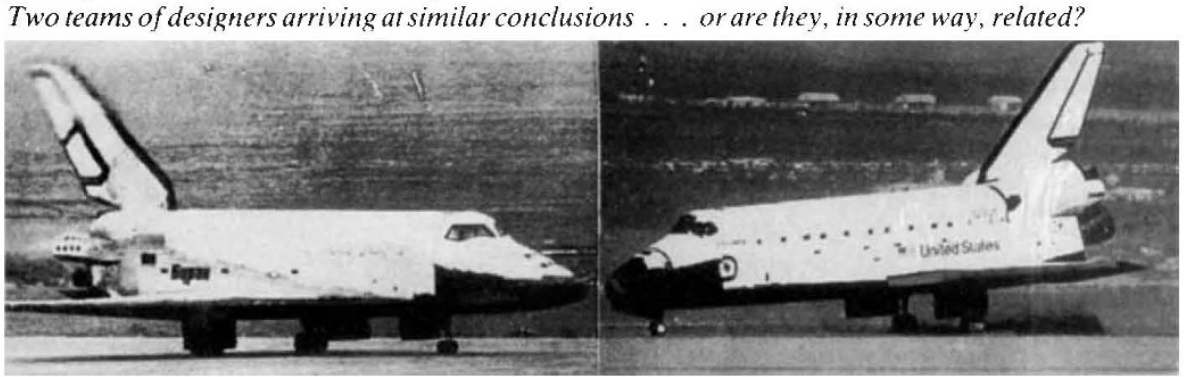
landing strips in the west and east of the Soviet Union. Up to three reusable spacecraft will be used in the future, each of them launched up to four times a year.

On the reason why Buran's first flight was unmanned, Dunayev explains that it is important "to astronautics and for aviation" to demonstrate this capacity, but also that the first flight will help determine when the first manned Soviet flights will take place. He says that the second flight "may also be unmanned".

Mikhail Chernyshov Novosti

\section{a success in the West}

In the United States, there has been much speculation over how much Buran's designers learnt from studying the US space shuttle. But Pike claims that the "closer you look at the Soviet shuttle the less it looks like the US shuttle". He points out that the wing shape is different, the nose more pointed, and the payload bay doors narrower. Altogether he believes that "clear pictures would probably show more differences than between the Boeing 767 and the European Airbus".

Differences in design can be seen in such key items as the tiles which cover the shuttle and protect it from extreme heat as it reenters the atmosphere. Each of the 22,000 tiles that cover the US shuttle is numbered and fits in only one place. But television close-ups of Buran show the tiles are not numbered and are apparently of a uniform design.

The biggest difference between the two shuttles, that Buran has no rocket engine of its own, may make the Soviet programme a more expensive one to run. Buran relies entirely on reaching orbit through the action of the enormous Energia rocket and four strap-on, liquid-fuel boosters. As the Energia rocket cannot be recovered, each launch costs the Soviet Union a new set of rocket motors. The US shuttle's three main engines are re-usable.

Soviet costs will also be pushed up because its overheads will be spread over fewer launches than the US programme.

Alun Anderson or are they, in some way, related?

are Valentin Glushko, Yuri Semenov and Boris Gubanov, who also designed the complicated launching and landing facilities. Apart from the $5-\mathrm{km}$ landing strip near here, there will be two emergency 